\title{
Hip fracture mortality in patients co-infected with coronavirus disease 2019: a comparison of the first two waves of the United Kingdom pandemic during the pre-vaccine era
}

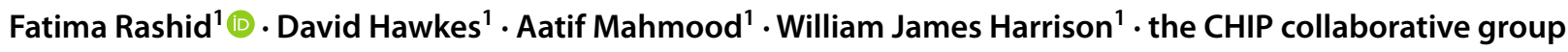

Received: 13 October 2021 / Accepted: 14 November 2021 / Published online: 9 January 2022

(c) The Author(s) under exclusive licence to SICOT aisbl 2021

\begin{abstract}
Aims In the UK, deaths associated with COVID-19 have occurred in two waves. Evidence has shown an increase in 30-day mortality for hip fracture patients co-infected with COVID-19. However, there are no studies analysing mortality trends between the first two waves of the UK pandemic. Additionally, hospital versus community acquired COVID-19 infection between the two waves has not been analysed. Furthermore, predictive factors of 30-day mortality have not been fully evaluated.

Methods Data from two audits conducted by the CHIP collaborative group were used: a published regional audit in England of nine hospitals providing the COVID-19 negative cases and an unpublished UK national audit of 43 hospitals, which provided the COVID-19 positive cases. Data collection for the COVID-19 positive cases was from 23 March to 31 December 2020. September 1, 2020 was used to define the transition between the two waves.

Results There were 517 COVID-19 positive hip fracture patients and 1445 COVID-19 negative hip fracture patients. Overall, 30-day mortality rates were 5.7\% in the COVID-19 negative group and $22.4 \%$ in the COVID-19 positive patients $(p<0.001)$. A difference in survival function between the first and second waves was found $(p=0.038)$. To allow for significant demographic differences, a matched analysis of 185 patients found a 26.5\% 30-day mortality in the first wave compared to $21.1 \%$ in the second wave $(p=0.222)$. Within the COVID-19 positive groups, the virus was hospital acquired in $66.7 \%$ of cases in the first wave and $72.8 \%$ of cases in the second wave $(p=0.130)$. Independent predictors of mortality were found to include COVID-19 positive status, AMTS $\leq 6$, male gender and age.

Conclusion There was a reduction in 30-day mortality for hip fracture patients co-infected with COVID-19 between the two UK pandemic waves but this was not statistically significant. There was no reduction in hospital acquired COVID-19 infection between the two waves.
\end{abstract}

Keywords COVID-19 $\cdot$ Hip fracture $\cdot$ Mortality $\cdot$ Pandemic

\section{Introduction}

The COVID-19 pandemic emerged in the UK with the first reported case in February 2020. Since then, the virus has caused undue stress on the National Health Service with over 149,000 associated deaths [1]. According to the national statistics the distribution of deaths has occurred in two main waves, March to August 2020 and September to February

Fatima Rashid

fatimarashid@doctors.org.uk

1 The Countess of Chester NHS Foundation, Liverpool Road, Chester CH2 1UL, UK
2021 [1]. Evidence suggests this is in a similar fashion to previous pandemic outbreaks such as the Spanish flu [2].

COVID-19 has been shown to cause the highest mortality in the elderly and those with co-morbidities [3]. Hip fracture patients are amongst the most vulnerable cohort and make up a large proportion of orthopaedic trauma. The National Institute for Health and Care Excellence (NICE) and Best Practice Tariff in the UK has streamlined care for this group in order to reduce mortality and morbidity associated with sustaining a hip fracture. According to the UK National Hip Fracture Database mortality rates have decreased since the introduction of these care pathways with a national mortality rate of $6.5 \%$ in 2019 [4]. 
However, several studies have found that a patient sustaining a hip fracture with concomitant COVID-19 infection has a significantly increased mortality rate. Wright et al. found a mortality rate of $11.7 \%(2 / 17)$ [5], Vives et al. 30.4\% (7/23) [6], Kayani et al. 30.5\% (25/82) [7], Hall et al. 33.3\% (9/27) [8], Egol et al. 35.3\% (6/17) [9], Arafa et al. 36.8\% (7/19) [10], Wignall et al. 38.2\% (13/24) [11] and Farii et al. 40\% (20/50) [12]. Similarly, metaanalyses conducted by Wang et al. (16 studies) and Lim and Pranata (6 studies) found mortality rates of $32.6 \%$ [13] and 36\% [14], respectively. These studies were all conducted within the first wave of the pandemic, prior to 1 June 2020.

COVID-19 has been shown to be an independent risk factor for mortality $[8,15]$. Other factors that comprise the Nottingham Hip Fracture Score (NHFS) have previously been validated to predict 30-day mortality [3]. Prior to the pandemic, Wiles et al. showed that a NHFS $>4$ yields a 30 -day mortality of $13.7 \%$ compared with $3.5 \%$ with a NHFS $<4$ [16]. Tsang et al. provided 30-day mortality rates associated with individual parameters, postulating that the $\mathrm{Hb}$ level had the highest impact on mortality, $10.7 \%$ followed by presence of malignant disease $10.2 \%,>90$ years of age $9.6 \%$, male sex 9.3\%, living in an institution 9.1\% and an Abbreviated Mental Test Score (AMTS) $<78.9 \%$ [17].

Our previous regional audit conducted in the North West of England of 1633 patients from 23 March to 23 June, comparing 30-day mortality rates in matched data sets, found mortality increased from $6.8 \%$ (2019 patients) to $35.6 \%$ (63/177) in COVID-19 positive patients [15]. This study has the largest number of COVID-19 positive patients and the longest time frame spanning until 23 June 2020 amongst currently published studies.

Broader studies have shown a reduced case fatality rate for COVID-19 patients without associated fractures as the pandemic has progressed [18], but no analysis to date has considered whether or not these improvements apply to the hip fracture population. Currently, there are no studies expressing the mortality of hip fracture patients infected with COVID- 19 beyond June 2020 and therefore no publications analysing the progression of the pandemic within the hip fracture population over the last year, with comparison between the pandemic waves.

The primary aim of this UK national audit was to compare the mortality in hip fracture patients co-infected with COVID-19 between the first two waves of the UK pandemic. Secondary outcomes included analysis of possible predictors of 30-day mortality including age, male sex, admitted from institution, co-morbidities, presence of malignancy, AMTS, haemoglobin level, NHFS and time to surgery for COVID-19 positive status hip fracture patients. Further secondary outcomes were comparison of hospital versus community acquired COVID-19 infection, time to theatre and rates of total hip replacement procedures between waves of the pandemic.

\section{Methods}

Data was analysed from a published regional observational audit carried out in the North West of England (CHIP 1) [15], and an unpublished national audit carried out in 43 hospital NHS trusts in England, Wales, Scotland and Northern Ireland (CHIP 2) [19], both conducted by the same authorship group. The audits were approved and registered at the leading trust (registration numbers 24107 and 24,459 ) and at each collaborating hospital.

CHIP 1 data was collected from 23 March (date of UK lockdown) to 23 June 2020 with mortality tracing to 23 July 2020. For control purposes the 2019 data was collected from the same period 23 March to 23 June 2019. CHIP 2 data was collected from 23 March to 31 December 2020, with mortality tracing to 31 January 2021.

The inclusion criterion was all hip fracture patients over the age of 60. Exclusion criteria were femoral shaft fractures (defined as a fracture greater than $5 \mathrm{~cm}$ below the lesser trochanter), periprosthetic femur fractures, pelvic or acetabular fractures, pathological fractures, open fractures and conservatively managed patients.

Each Principal Investigator (PI) at each hospital identified patients from a prospective database used to submit to the UK National Hip Fracture Database (NHFD). Data points required for the study including identification of mortality were found from individual patient records. A patient was considered to be infected with COVID-19 if confirmed with a Polymerase Chain Reaction (PCR) test. We defined community acquired infection for those patients who had COVID-19 positive PCR on admission and hospital acquired for those who tested negative on admission but subsequently became positive during their inpatient stay.

Data collected included age, sex, residence, ASA grade, AMTS, number of co-morbidities, active or history of malignancy, admission $\mathrm{Hb}$ level, vitamin D level, fracture type, surgical intervention, date of admission and discharge, date and time of surgery, type of surgery performed, review by ortho-geriatrician, 30-day mortality and COVID-19 status including timing of PCR tests (on or during admission). The NHFS, timing of surgery and length of stay were calculated from the collected data.

Data was uploaded onto specifically designed webbased forms with limited free text boxes to increase consistency and reliability. Each PI had the opportunity to clarify any uncertainties through continual contact with the study leads. The web-based forms automatically populated corresponding spreadsheets. Data collection was 
in accordance with UK Caldicott principles [20] and in line with hospital information governance guidelines. No patient identifiable data was uploaded and it was not possible to back trace any patients. Informed consent and ethical approval therefore was not required.

According to the UK national statistics the maximal dip in the waves occurred 1 September 2020, and therefore, this date was used to define the transition between the two waves [1]. The first wave defined as 23 March to 31 August 2020 and the second wave 1 September to the end of our data collection (31 December 2020).

Statistical analysis was performed using IBM SPSS Statistics (version 27). Continuous data is presented and means ( \pm standard deviation (SD)) and categorical data summarised with absolute and relative frequencies. Continuous variables were compared across study groups with an analysis of variance (ANOVA), with post-hoc testing using a Bonferroni correction as appropriate. Comparisons for categorical data were made using the Chi-square test. A Kaplan-Meier survival analysis compared survivorship between the study groups and the generalised Wilcoxon test was used to test for significant differences. The baseline demographic variables for the COVID-19 positive groups differed; therefore, a matched sub-analysis was performed in order to eliminate the effect of these confounding variables when assessing mortality between the groups. Binary logistic regression was used to calculate adjusted odds ratios and identify independent predictors of 30 -day mortality. $P$-values $<0.05$ were considered to be statistically significant.

\section{Results}

The study group comprised of 517 COVID-19 positive patients from 43 different hospital Trusts across England, Wales, Scotland and Northern Ireland. These 517 patients were all recorded in our second (national) unpublished audit. There were 1445 COVID-19 negative control patients which had been recorded in our earlier published CHIP 1 regional audit conducted in the North West of England [15]. Thus, this new study comprised four patient groups for analysis: 234 patients who were COVID-19 positive in the first wave, 283 patients COVID-19 positive in the second wave, 825 patients in the COVID-19 negative 2019 pre-pandemic control cohort and 620 COVID-19 negative patients in the 2020 during pandemic control cohort.

\section{Demographics of the study population}

The overall mean age of the study population was 82.4 years. Post-hoc testing revealed that there were significant differences across the study cohorts, with the mean age significantly higher in the COVID-19 positive first wave as compared to the control patients 2019 and COVID-19 negative 2020 cohorts $(p<0.001)$. There were no significant differences in mean age between the COVID-19 positive first and second waves $(p=0.227)$ and between the COVID19 positive second wave and the COVID-19 negative groups $(p=0.082-0.332)$ (Table 1).

Gender differences were significantly different across the study groups. There was a significantly greater proportion of males in the COVID-19 positive groups $(30.0 \%)$ as compared to the COVID-19 negative groups $(24.7 \% ; p=0.014)$, but no significant differences when comparing the COVID19 positive first wave and COVID-19 positive second wave cohorts $(p=0.111)$.

A significantly greater proportion of patients were admitted from an institution in the COVID-19 positive first wave, as compared to the COVID-19 positive second wave $(p<0.001)$ and the COVID-19 negative cohorts $(p<0.001)$. There were no differences between usual place of residence between the COVID-19 positive second wave and the COVID-19 negative cohorts $(p=0.896)$ (Table 1$)$.

The COVID-19 positive groups were more likely to be co-morbid $(p<0.001)$, have a lower AMTS score $(p<0.001)$ and have a lower $\mathrm{Hb}$ on admission $(p=0.008)$ (Table 1). The mean NHFS was significantly higher in the COVID19 positive first wave cohort as compared to the three other groups $(p<0.001-0.012)$. Interestingly however, the mean NHFS was significantly lower in the COVID-19 positive second-wave cohort as compared to the other groups $(p<0.001-0.002)$. There were no significant differences in mean NHFS between the COVID-19 negative 2019 and 2020 groups (Table 1 ).

Considering the COVID-19 positive groups, the virus was hospital acquired in $66.7 \%$ of cases in the first wave and $72.8 \%$ of cases in the second wave $(p=0.130)$. A subanalysis of the community acquired cases identified that $63.9 \%$ of patients in the first wave were admitted from an institution, as compared to $36.1 \%$ in the second wave $(p=0.002)$.

\section{Mortality}

Overall 30-day mortality rates were $5.7 \%$ in the COVID19 negative patients and $22.4 \%$ in the COVID-19 positive patients $(p<0.001)$ (Table 1). Figure 1 gives the overall number of COVID-19 positive admissions by month, with the corresponding mortality rates. Figure 2 gives a survival analysis comparing the study cohorts. Applying the generalised Wilcoxon test identified differences in survival function between the COVID-19 positive first and second waves $(p=0.038)$. Survivorship was also significantly lower in the COVID-19 positive first and second waves to the COVID-19 negative 2019 and 2020 groups $(p<0.001$ 
Table 1 Mortality, demographics and clinical characteristics

\begin{tabular}{|c|c|c|c|c|c|c|}
\hline \multirow[t]{2}{*}{ Variable } & & \multicolumn{2}{|l|}{ COVID-19 negative } & \multicolumn{2}{|l|}{ COVID-19 positive } & \multirow{2}{*}{$\begin{array}{l}\text { Group } \\
\text { comparison } \\
p \text {-value }\end{array}$} \\
\hline & & 2019 cohort $(n=825)$ & 2020 cohort $(n=620)$ & First wave $(n=234)$ & $\begin{array}{l}\text { Second wave } \\
(n=283)\end{array}$ & \\
\hline \multirow[t]{2}{*}{ 30-day mortality } & Dead & $41(5.0 \%)$ & $42(6.8 \%)$ & $61(26.1 \%)$ & $55(19.4 \%)$ & \multirow[t]{2}{*}{$<\mathbf{0 . 0 0 1}^{\dagger}$} \\
\hline & Alive & $784(95.0 \%)$ & $578(93.2 \%)$ & $173(73.9 \%)$ & $228(80.6 \%)$ & \\
\hline Age (years) & & $82.0 \pm 8.3$ & $81.2 \pm 9.2$ & $84.8 \pm 7.7$ & $83.2 \pm 8.7$ & $<0.001 *$ \\
\hline \multirow[t]{2}{*}{ Gender } & Male & $236(28.6 \%)$ & $189(30.5 \%)$ & $91(38.9 \%)$ & $91(32.2 \%)$ & \multirow[t]{2}{*}{$\mathbf{0 . 0 2 6}{ }^{\dagger}$} \\
\hline & Female & $589(71.4 \%)$ & $431(69.5 \%)$ & $143(61.1 \%)$ & $192(67.8 \%)$ & \\
\hline \multirow[t]{2}{*}{ Place of residence } & $\begin{array}{l}\text { Own home/ } \\
\text { ward con- } \\
\text { trolled }\end{array}$ & $652(79.0 \%)$ & $497(80.2 \%)$ & $142(60.7 \%)$ & $226(79.9 \%)$ & \multirow[t]{2}{*}{$<0.0011^{\dagger}$} \\
\hline & Institution & $173(21.0 \%)$ & $123(19.8 \%)$ & $92(39.3 \%)$ & $57(20.1 \%)$ & \\
\hline \multirow{2}{*}{$\begin{array}{l}\text { Number of comor- } \\
\text { bidities }\end{array}$} & Less than 2 & $391(47.4 \%)$ & $291(46.9 \%)$ & $59(25.2 \%)$ & $103(36.4 \%)$ & \multirow[t]{2}{*}{$<\mathbf{0 . 0 0 1} 1^{\dagger}$} \\
\hline & 2 or more & $434(52.6 \%)$ & $329(53.1 \%)$ & $175(74.8 \%)$ & $180(63.6 \%)$ & \\
\hline \multirow{2}{*}{$\begin{array}{l}\text { Active or previous } \\
\text { malignancy }\end{array}$} & Yes & $126(15.3 \%)$ & $98(15.8 \%)$ & $43(18.4 \%)$ & $60(21.2 \%)$ & \multirow[t]{2}{*}{$0.104^{\dagger}$} \\
\hline & No & $699(84.7 \%)$ & $522(84.2 \%)$ & $191(81.6 \%)$ & $223(78.8 \%)$ & \\
\hline \multirow[t]{2}{*}{ AMTS } & $\geq 7$ & $567(69.8 \%)$ & $421(68.7 \%)$ & $100(46.7 \%)$ & $177(66.3 \%)$ & \multirow[t]{2}{*}{$<\mathbf{0 . 0 0 1}^{\dagger}$} \\
\hline & $\leq 6$ & $245(30.2 \%)$ & $192(31.3 \%)$ & $114(53.3 \%)$ & $90(33.7 \%)$ & \\
\hline \multirow[t]{2}{*}{$\mathrm{Hb}$ on admission } & $<10 \mathrm{~g} / \mathrm{dL}$ & $97(11.8 \%)$ & $84(13.5 \%)$ & $43(18.4 \%)$ & $52(18.4 \%)$ & \multirow[t]{2}{*}{$\mathbf{0 . 0 0 8}^{\dagger}$} \\
\hline & $\geq 10 \mathrm{~g} / \mathrm{dL}$ & $728(88.2 \%)$ & $536(86.5 \%)$ & $191(81.6 \%)$ & $231(81.6 \%)$ & \\
\hline NHFS & & $5.6 \pm 1.3$ & $5.5 \pm 1.5$ & $5.9 \pm 1.6$ & $5.2 \pm 1.5$ & $<0.001$ \\
\hline
\end{tabular}

$p$-values compare differences across all groups. ${ }^{\dagger}$ Chi-squared test. *ANOVA. Significant values are given in bold

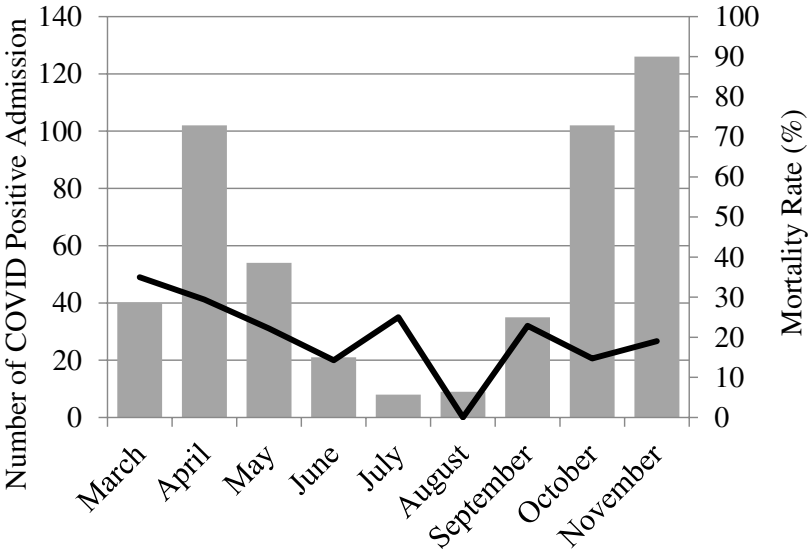

Fig. 1 Monthly admissions (grey bars) and monthly mortality rate (black line) for the COVID-19 positive patients. The month of December is excluded as an incomplete data set for December was submitted by some of the participating hospitals

and $p<0.001$, respectively). There were no differences in survival between the COVID-19 negative 2019 and the 2020 cohorts $(p=0.119)$.

Significant differences in demographic characteristics between the COVID-19 positive first wave and second wave cohorts were seen, as previously highlighted. A matched analysis was therefore undertaken to eliminate the effects of these confounding variables and identify if these mortality differences between waves were true, or simply a function of the differing patient characteristics. This sub-analysis comprised of 185 cases from the first wave and 185 cases from the second wave matched exactly on NHFS (there were 147 unmatched cases). Thirty-day mortality in the first wave was $26.5 \%$ as compared to $21.1 \%$ in the second wave, and this was not statistically significant $(p=0.222)$.

\section{Risk factors for mortality}

Logistic regression was used to identify the independent predictors of 30-day mortality across the entire four study and control groups by adjusting for confounding variables. Age, male gender, AMTS $\leq 6$ and a COVID19 positive status were all identified to be independent predictors. The effect size was largest for a COVID19 positive status with an adjusted OR of 4.00 (95\% $\mathrm{CI}=2.77-5.76)$ (Table 2).

\section{Orthopaedic management}

There were no differences in the fracture type across any of the study groups. Similarly, there were no differences in whether arthroplasty or fixation was performed when comparing the COVID-19 negative and the COVID-19 positive cohorts (COVID-19 negative: arthroplasty $52.0 \%$ vs fixation 
Fig. 2 Kaplan-Meier survival analysis comparing the study cohorts

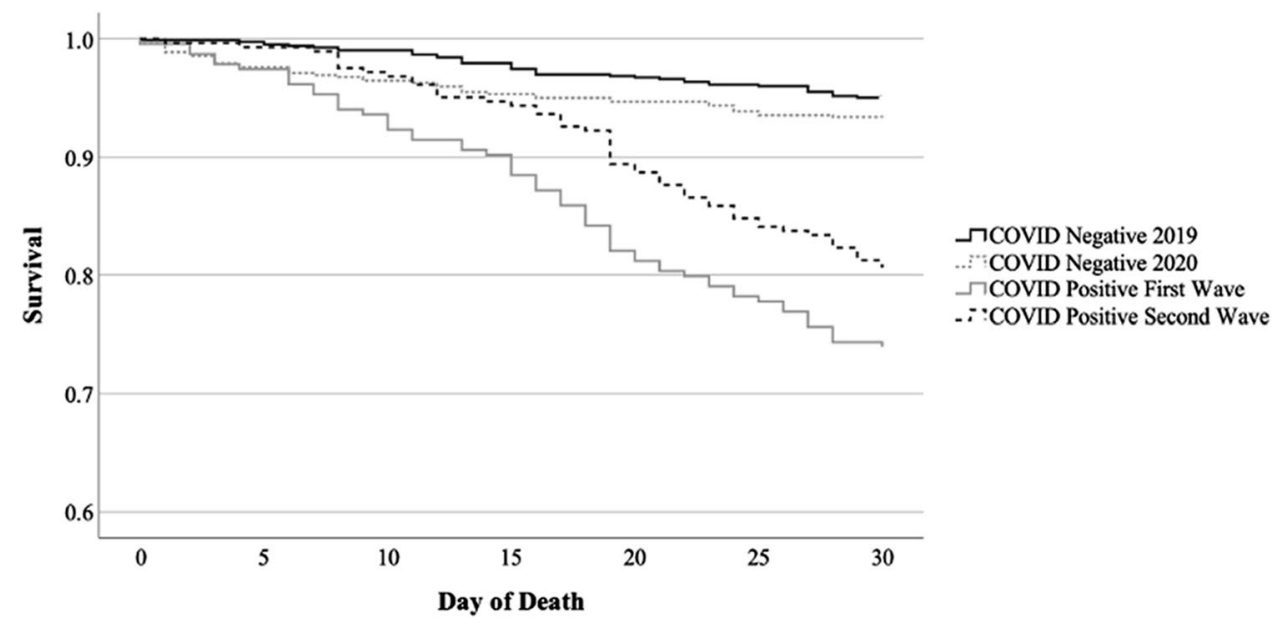

Table 2 Logistic regression analysis to identify predictors of 30-day mortality

\begin{tabular}{llr}
\hline Variable & Adjusted odd ratio $\pm 95 \%$ CI & $p$-value \\
\hline Age* & $1.05(1.01-1.09)$ & $\mathbf{0 . 0 1 5}$ \\
Male gender & $1.71(1.04-2.82)$ & $\mathbf{0 . 0 3 5}$ \\
Admitted from institution & $0.93(0.55-1.56)$ & 0.779 \\
2 or more comorbidities & $1.36(0.82-2.25)$ & 0.240 \\
No previous malignancy & $0.99(0.58-1.69)$ & 0.960 \\
AMTS $\leq 6$ & $2.07(1.36-3.15)$ & $\mathbf{0 . 0 0 1}$ \\
Hb $<10$ & $0.94(0.54-1.63)$ & 0.819 \\
NHFS* & $1.03(0.73-1.46)$ & 0.867 \\
Time to theatre $>36$ h & $1.30(0.93-1.81)$ & 0.130 \\
COVID-19 positive status & $4.00(2.77-5.76)$ & $<\mathbf{0 . 0 0 1}$ \\
\hline
\end{tabular}

CI confidence interval. *Continuous variables. Significant values are given in bold
48.0\%; COVID-19 positive: arthroplasty $51.7 \%$ vs fixation $48.3 \% ; p=0.918)$. However, in the arthroplasty patients, rates of total hip replacement (THR) were significantly lower in the COVID-19 positive cohort (4.1\%) as compared to the COVID-19 negative group $(14.5 \%)(p<0.001)$. In the fixation patients, the rates of DHS and intramedullary nailing did not vary according to COVID-19 status $(p=0.843)$ (Table 3).

There was no difference in time to theatre between any of the study groups $(p=0.119)$. However, length of stay was significantly shorter in the COVID-19 negative 2020 cohort, as compared to the COVID-19 negative 2019 cohort $(p<0.001)$. Length of stay was significantly shorter in the COVID-19 negative 2019 and 2020 cohorts as compared to the COVID-19 positive first wave $(p=0.035$ and $p<0.001$, respectively) and the COVID-19 positive second wave $(p<0.001$ and $p<0.001$, respectively). There were no

Table 3 Fracture type, surgical procedure and length of stay

\begin{tabular}{|c|c|c|c|c|c|c|}
\hline \multirow[t]{2}{*}{ Variable } & & \multicolumn{2}{|c|}{ COVID-19 negative } & \multicolumn{2}{|l|}{ COVID-19 positive } & \multirow{2}{*}{$\begin{array}{l}\text { Group } \\
\text { comparison } \\
p \text {-value }\end{array}$} \\
\hline & & $\begin{array}{l}2019 \text { cohort } \\
(n=825)\end{array}$ & $\begin{array}{l}2020 \text { cohort } \\
(n=620)\end{array}$ & First wave $(n=234)$ & $\begin{array}{l}\text { Second wave } \\
(n=283)\end{array}$ & \\
\hline \multirow[t]{3}{*}{ Fracture type } & Intracapsular & $485(58.8 \%)$ & $360(58.1 \%)$ & $138(59.0 \%)$ & $156(55.1 \%)$ & \multirow[t]{3}{*}{$0.740^{\dagger}$} \\
\hline & Extracapsular & $290(35.2 \%)$ & $213(34.4 \%)$ & $81(34.6 \%)$ & $102(36.0 \%)$ & \\
\hline & Subtrochanteric & $50(6.1 \%)$ & $47(7.6 \%)$ & $15(6.4 \%)$ & $25(8.8 \%)$ & \\
\hline \multirow[t]{5}{*}{ Procedure } & Hemiarthroplasty & $356(43.2 \%)$ & $284(45.8 \%)$ & $122(52.1 \%)$ & $134(47.5 \%)$ & \multirow[t]{5}{*}{$<\mathbf{0 . 0 0 1}^{\dagger}$} \\
\hline & THR & $71(8.6 \%)$ & $40(6.5 \%)$ & $5(2.1 \%)$ & $6(2.1 \%)$ & \\
\hline & DHS & $253(30.7 \%)$ & $184(29.7 \%)$ & $68(29.1 \%)$ & $79(28.0 \%)$ & \\
\hline & IM nail & $138(16.7 \%)$ & $104(16.8 \%)$ & $31(13.2 \%)$ & $53(18.8 \%)$ & \\
\hline & Other & $6(0.7 \%)$ & $8(1.3 \%)$ & $8(3.4 \%)$ & $10(3.5 \%)$ & \\
\hline \multicolumn{2}{|c|}{ Time to theatre (h) } & $35.1 \pm 37.8$ & $33.4 \pm 63.7$ & $42.6 \pm 56.1$ & $36.4 \pm 40.6$ & $0.119 *$ \\
\hline \multicolumn{2}{|c|}{ Length of stay (days) } & $18.5 \pm 16.1$ & $13.0 \pm 17.8$ & $22.3 \pm 20.2$ & $25.6 \pm 17.9$ & $<0.001 *$ \\
\hline
\end{tabular}

$p$-values compare differences across all groups. ${ }^{\dagger}$ Chi-squared test. *ANOVA. Significant values are given in bold 
differences in length of stay between the COVID-19 positive first and second waves $(p=0.265)$ (Table 3$)$.

\section{Discussion}

\section{Between the two waves}

Analysis between the two UK waves revealed no difference in mean age or proportion of males. However, there was a significant difference in the NHFS, with a higher score in the first wave compared with COVID-19 negative controls and a significantly lower score in the second wave, suggesting a frailer cohort in the first wave. A potential explanation could be due to the 'lockdown effect'. Frailer patients are more likely to sustain their hip fractures within their homes or institutions, with the less frail sustaining their hip fractures outside. The lockdown therefore forced the less frail to remain in doors during the first wave and thereby protecting them from falls. As the lockdown eased in the second wave, the less frail began venturing out, and possibly accentuated by deconditioning, were more unsteady, leading to increased likelihood of sustaining a hip fracture.

Our primary aim was to evaluate the mortality in hip fracture patients co-infected with COVID-19 between the two waves of the UK pandemic. This is the largest study yet to report and the first to analyse across the pandemic waves. The mortality in the first wave was $26.1 \%$ and lower in the second wave, $19.4 \%$. Survival analysis also showed a difference, and this was statistically significant $(p=0.038)$. To adjust for the confounding NHFS, a matched analysis between the first and second waves presented mortality rates of $26.5 \%$ and $21.1 \%$, respectively, which was not statistically significant. Thus, we believe that the apparent reduction in mortality between the waves may partly have been driven by the confounding influence of different patient demographics.

Although the mortality rates observed in our study are corroborated with previously published studies [8, 13, 14], they are somewhat lower than our previously published audit [15] and other smaller earlier studies. There may have been some reduction in mortality in the second wave secondary to the introduction of dexamethasone administration in July 2020 as it was demonstrated to reduce 28-day mortality rates in patients diagnosed with COVID19 [21]. The lower mortality rates than previously reported may also perhaps be explained by the small size of early studies, or some under-reporting of deaths in our study if some patients died in the community after discharge. Our reporting system remained consistent throughout our study and should allow reasonable comparison between the waves.

\section{Risk factors for mortality}

Independent risk factors of 30-day mortality were found to be COVID-19 positive status, AMTS $\leq 6$, male gender and age, in descending order of effect size. Recent published studies support the impact of COVID-19 having at least a four-fold increase in mortality when accounting for other confounders [8, 13-15]. Previous literature also supports the effect of age, male gender and AMTS on mortality; however, our study proposes that AMTS and male gender have a bigger effect on mortality than other factors such as age and co-morbidities [17]. This is important to consider when using the NHFS to predict 30-day mortality during the pandemic, as the NHFS gives age $>85$ a heavier weighting compared with AMTS or male gender.

We analysed low vitamin D as a risk factor for mortality in our CHIP2 study [19] and found no association in our group of 517 study patients despite having observed a nonsignificant trend towards an association in our earlier smaller CHIP1 study [15].

\section{Hospital and community acquired COVID-19}

We found that there was no difference between the number of hospital acquired COVID-19 infections between the two waves, suggesting that despite strict infection control, hip fracture patients were frequently contracting COVID-19 within hospitals.

During the second wave, in the UK $17.6 \%$ of all COVID19 infections appeared to be healthcare associated infections [18]. A major trauma centre in England found that $81.2 \%$ of COVID-19 infection in hip fracture patients were hospital acquired [22] and Lakhani et al. found age and length of hospital stay as significant factors for hospital acquired COVID-19 [23].

It is difficult to ascertain why transmission in hospitals has not decreased. Possible explanations include greater number of COVID-19 positive inpatients and more difficulty maintaining adequate infection control over time. Zheng et al. reported an increase in COVID-19 rates amongst healthcare workers, which may also have contributed [24]. This is of some concern and requires further studies in order to inform improved infection control processes in future COVID-19 outbreaks.

\section{Time to theatre, length of stay and surgery type}

Our study showed no difference in time to theatre between waves or compared with controls. The length of stay was also no different between waves. However, length of stay was significantly shorter in the COVID-19 negative 2020 cohort compared with 2019 cohort, which may be due to the practice of rapid discharge of COVID-19 negative patients to 
prevent them contracting COVID-19 in hospital. We found that for intracapsular hip fractures, rates of THR were significantly lower in the COVID-19 positive patients. This may be due to following British Orthopaedic Association guidelines [25] on selecting hemiarthroplasty over THR to allow simpler surgery, aiming to reduce mortality. It may also reflect that COVID-19 patients were more frail in the first wave, although the trend to reduced THR was maintained in both waves.

This study took place in the pre-vaccine era of the pandemic. Vaccines have subsequently been shown to reduce mortality in COVID-19 infected individuals [26, 27]. We suggest that clinicians should assess the COVID-19 vaccine history of all hip fracture patients now presenting to hospitals and offer immunisation or a booster dose to all unprotected or inadequately protected individuals. Further studies will be required to define the impact of vaccination on mortality in hip fracture patients, both when administered pre-injury, and when given post-injury to compensate for inadequate existing immunity.

\section{Limitations}

This is an observational study of a retrospective design, although data was collected prospectively as part of the NHFD. Some positive diagnoses of COVID-19 could have been missed for lack of testing, or because they became positive after hospital discharge. Some patient deaths may have been missed if they occurred after discharge and had not been informed back to the treating hospitals. No attempt was made to assess severity of infection, other than mortality. The definition used for community versus hospital acquired COVID-19 is simplistic, and some patients with community acquired disease could have been mis-categorised as hospital acquired. Our control patients were recruited prepandemic and in the first wave but not during the second wave.

\section{Conclusion}

There was no significant difference in 30-day mortality for hip fracture patients co-infected with COVID-19 between the two UK pandemic waves after adjusting for frailty.

There was no reduction in hospital acquired COVID-19 infection between the two waves.

Acknowledgements The authors would like to acknowledge the CHIP collaborative group at 43 hospital NHS Trusts:

Sophie Miller (Northern General Hospital), Shoaib Khan, Mohammed As-Sultany (Warrington and Halton Hospitals), Mathias Nagy (Wigan Infirmary), Gautam Reddy (Leeds General Infirmary), Richard Limb, Nasri Zreik (Liverpool University Foundation Trust), Ebrahim
Mahomed (Royal Lancaster Infirmary), Josh Howard (Grange University Hospital), Prakash Palaparthy (Russells Hall Hospital), Aadam Shah (Royal Preston Hospital), Calvin Mathias (New Cross Hospital), Mohammed As-Sultany, Graeme Wilson (Arrowe Park Hospital), Vishvas Shetty (Barnet Hospital), Abu Saeed (Worcestershire Acute Hospitals NHS Trust), Rory Cuthbert (Whittington Health NHS Trust), Surendra Patnaik (East Surrey Hospital), Nasri Zreik, Carol Chan (Whiston Hospital), Jehan Zaib (Hull University Teaching Hospital), Yusuf Hasan (John Radcliffe Hospital), Mark Sykes (Watford General Hospital), Andrea Pujol (Sunderland Royal Hospital), Donald Osarumwense (Sandwell and West Birmingham Hospitals), Aleksandra Adamczyk (Basildon and Thurrock University Hospitals), Tom Cash, Richard Limb (Macclesfield District General Hospital), Akshdeep Bawa (Princess Royal University Hospital), Tom Havenhand (Royal Oldham Hospital), Muhammed Amer Bashir (North Middlesex University Hospital), Rebecca Critchley (Royal Victoria Infirmary), Ibrahim Jaly (Queen Elizabeth Hospital, Birmingham), Muyed Mohamed Ibrahim Jaly (Southport District General Trust), Tom Cash (Leighton Hospital), Wayne Ng Weiyun (University Hospital Coventry \& Warwickshire), Anthony Gibbon (York Teaching Hospital), Srikanth Mudiganty (East Lancashire Hospitals Trust), Salman Ali (Barking, Havering and Redbridge University Hospitals NHS Trust), Shan Rias (Wrexham Maelor Hospital), Wahidun Nabi (Princess Alexandra Hospital), Jason Ong, Tureb Syed (Forth Valley Royal Hospital), Sam Trowbridge (Guy's and St Thomas' NHS trust), Mark Harris (Bristol Royal Infirmary), Sanket Gandhi (Horton General Hospital), Panagiotis Armoni (University College London Hospital), Shayra Khanom (Royal Free London) and Moritz Lebe (Broomfield Hospital).

Author contribution F Rashid: Designed the study and audit tool. Collected and interpreted the data. Wrote the manuscript.

D Hawkes: Interpreted and statistically analysed the data. Wrote the manuscript.

A Mahmood: Designed the study and audit tool. Collected and interpreted the data.

WJ Harrison: Designed the study. Interpreted the data. Wrote and reviewed the manuscript.

Availability of data and materials Original data collection can be provided if requested.

\section{Declarations}

Ethical approval, consent to participate and consent to publish Data collection was in accordance with UK Caldicott principles and in line with hospital information governance guidelines. No patient identifiable data was uploaded and it was not possible to back trace any patients. Informed consent to participate/publish and ethical approval therefore was not required.

Conflict of interest The authors declare no competing interests.

\section{References}

1. No authors listed (accessed April 2021). https://coronavirus.data. gov.uk/details/deaths

2. He D, Zhao S, Li Y, Cao P, Gao D, Lou Y et al (2020) Comparing COVID-19 and the 1918-19 influenza pandemics in the United Kingdom. Int J Infect Dis 98:67-70. https://doi.org/10.1016/j.ijid. 2020.06.075

3. Williamson EJ, Walker AJ, Bhaskaran K, Bacon S, Morton C, Curtis H et al (2020) Factors associated with COVID-19-related 
death using OpenSAFELY. Nature 584(7821):430-436. https:// doi.org/10.1038/s41586-020-2521-4

4. No authors listed (accessed April 2021). https://www.hqip.org.uk/ wp-content/uploads/2021/01/NHFD-Annual-Report-14-January. pdf

5. Wright EV, Musbahi O, Singh A, Somashekar N, Huber CP, Wiik AV (2021) Increased perioperative mortality for femoral neck fractures in patients with coronavirus disease 2019 (COVID19): experience from the United Kingdom during the first wave of the pandemic. Patient Saf Surg 15(1). https://doi.org/10.1186/ s13037-020-00279-x

6. Muñoz Vives M, Jornet-Gibert M, Cámara-Cabrera J, Esteban PL, Brunet L, Delgado-Flores L et al (2020) Mortality rates of patients with proximal femoral fracture in a worldwide pandemic: preliminary results of the Spanish HIP-COVID Observational Study. J Bone Joint Surg 102(13):e69. https://doi.org/10.2106/JBJS.20. 00686

7. Kayani B, Onochie E, Patil V, Begum F, Cuthbert R, Ferguson D et al (2020) The effects of COVID-19 on perioperative morbidity and mortality in patients with hip fractures: a multicentre cohort study. Bone Joint J 102-B(9):1136-45. https://doi.org/10.1302/ 0301-620X.102B9.BJJ-2020-1127.R1

8. Hall AJ, Clement N, Farrow L, MacLullich AMJ, Dall GF, Scott C et al (2020) IMPACT-Scot report on COVID-19 and hip fractures: a multicentre study assessing mortality, predictors of early SARS$\mathrm{CoV}-2$ infection, and the effects of social lockdown on epidemiology. Bone Joint J 102-B(9):1219-28. https://doi.org/10.1302/ 0301-620X.102B9.BJJ-2020-1100.R1

9. Egol KA, Konda S, Bird ML, Dedhia N, Landes E, Ranson R et al (2020) Increased mortality and major complications in hip fracture care during the COVID-19 pandemic: a New York City perspective. J Orthop Trauma 34(8):395-402. https://doi.org/10. 1097/BOT.0000000000001845

10. Arafa M, Nesar S, Abu-Jabeh H, Jayme MOR, Kalairajah Y (2020) COVID-19 pandemic and hip fractures: impact and lessons learned. Bone \& Joint Open 1(9):530-540. https://doi.org/ 10.1302/2633-1462.19.BJO-2020-0116.R1

11. Wignall A, Giannoudis V, De C, Jimenez A, Sturdee S, Nisar S et al (2021) The impact of COVID-19 on the management and outcomes of patients with proximal femoral fractures: a multicentre study of 580 patients. J Orthop Surg Res 16(1):155. https:// doi.org/10.1186/s13018-021-02301-z

12. Al Farii H, Al Rawahi S, Samaila E, Lavini F, Magnan B, Al Maskari S (2020) Thirty-day mortality in COVID-19 positive patients with hip fractures: a case-series and literature review. Geriatr Orthop Surg Rehabil 11:215145932097268. https://doi. org/10.1177/2151459320972681

13. Wang KC, Xiao R, Cheung ZB, Barbera JP, Forsh DA (2020) Early mortality after hip fracture surgery in COVID-19 patients: a systematic review and meta-analysis. J Orthop 22:584-591. https://doi.org/10.1016/j.jor.2020.11.012

14. Lim MA, Pranata R (2021) Coronavirus disease 2019 (COVID-19) markedly increased mortality in patients with hip fracture - a systematic review and meta-analysis. J Clin Orthop Trauma 12(1):187-193. https://doi.org/10.1016/j.jcot. 2020.09.015
15 Mahmood A, Rashid F, Limb R, Cash T, Nagy M, Zreik N et al (2021) Coronavirus infection in hip fractures (CHIP) study: a case-matched multicentre study of 1,633 hip fracture patients. Bone Joint J 103-B(4):782-7. https://doi.org/10.1302/0301-620X. 103B.BJJ-2020-1862.R1

16. Wiles MD, Moran CG, Sahota O, Moppett IK (2011) Nottingham Hip Fracture Score as a predictor of one year mortality in patients undergoing surgical repair of fractured neck of femur. $\mathrm{Br}$ J Anaesth 106(4):501-504. https://doi.org/10.1093/bja/aeq405

17. Tsang C, Boulton C, Burgon V, Johansen A, Wakeman R, Cromwell DA (2017) Predicting 30-day mortality after hip fracture surgery: evaluation of the National Hip Fracture Database case-mix adjustment model. Bone Joint Res 6(9):550-556. https://doi.org/ 10.1302/2046-3758.69.BJR-2017-0020.R1

18. No authors listed (accessed April 2021). https://www.cebm.net/

19. Mahmood A, Rashid F, Hawkes D, Harrison WJ, CHIP-2 collaborative group (Currently unpublished, 2021) Coronavirus in HIP fractures CHIP 2: is vitamin D deficiency associated with increased mortality from COVID-19 infections in a hip fracture population?

20. The Caldicott Report (1999) IHRIM. 40(2):17-9

21. The RECOVERY Collaborative Group (2021) Dexamethasone in hospitalized patients with Covid-19. N Engl J Med 384(8):693704. https://doi.org/10.1056/NEJMoa2021436

22. Ajayi B, Trompeter AJ, Umarji S, Saha P, Arnander M, Lui DF (2021) Catching the second wave: clinical characteristics and nosocomial infection rates in major trauma and orthopaedic patients during the COVID-19 pandemic. Bone Joint Open 2(8):661-670. https://doi.org/10.1302/2633-1462.28.BJO-20210078.R1

23. Lakhani K, Minguell K, Guerra-Farfan E, Lara Y, Jambrina U, Pijoan J, Nunez JH (2020) Nosocomial infection with SARSCoV-2 and main outcomes after surgery within an orthopaedic surgery department in a tertiary trauma centre in Spain. Int Orthop (SICOT) 44(12):2505-2513. https://doi.org/10.1007/ s00264-020-04798-1

24. Zheng C, Hafezi-Bakhtiari N, Cooper V, Davidson H, Habibi M, Riley P, Breathnach A (2020) Characteristics and transmission dynamics of COVID-19 in healthcare workers at a London teaching hospital. J Hosp Infect 106(2):325-329. https://doi.org/10. 1016/j.jhin.2020.07.025

25. No authors listed (accessed April 2020) Management of patients with urgent orthopaedic conditions and trauma during the coronavirus pandemic. British Orthopaedic Association. https://www. boa.ac.uk/resources/covid-19-boasts-combined.html

26. Moghadas SM, Vilches TN, Zhang K, Wells CR, Shoukat A, Singer BH, Meyers LA, Neuzil KM, Langley JM, Fitzpatrick MC, Galvani AP (Pre-print Nov 2020) The impact of vaccination on COVID-19 outbreaks in the United States.Clin Infect Dis.https:// doi.org/10.1093/cid/ciab079

27 Dyer O (2021) Covid-19: unvaccinated face 11 times risk of death from delta variant, CDC data show. BMJ 374:2282. https://doi. org/10.1136/bmj.n2282

Publisher's note Springer Nature remains neutral with regard to jurisdictional claims in published maps and institutional affiliations. 